\title{
Nutrient Restriction Impairs Nephrogenesis in a Gender-Specific Manner in the Ovine Fetus
}

\author{
JEFFREY S. GILBERT, STEPHEN P. FORD, A. LEE LANG, LINDSAY R. PAHL, MARK C. DRUMHILLER, SARA A. BABCOCK, \\ PETER W. NATHANIELSZ, AND MARK J. NIJLAND
}

\begin{abstract}
Center for the Study of Fetal Programming [J.S.G., S.P.F., A.L.L., L.R.P., M.C.D., P.W.N., M.J.N.], Departments of Zoology and Physiology [J.S.G., A.L.L., L.R.P.] Animal Science [S.P.F., M.C.D.], University of Wyoming, Laramie, Wyoming 82071; and Department of Obstetrics and Gynecology [J.S.G., S.A.B., P.W.N., M.J.N.] Center for Pregnancy and Newborn Research, University of Texas Health Science Center at San Antonio, San Antonio, Texas 78229
\end{abstract}

\begin{abstract}
Inadequate nutrition compromises fetal development and poses long-term health risks for the offspring, even without decreased birth weight. The present study sought to 1) establish the ontogeny of fetal renal glomerulus number (GN) in sheep and 2) evaluate the effects of $50 \%$ global nutrient restriction (NR) during early to midgestation on GN and the renin-angiotensin system in the fetal kidney. GN increased from $78 \mathrm{dG}(68,560 \pm 3802)$ to $135 \mathrm{dG}$ $(586,118 \pm 25,792)$. NR increased combined kidney weight $(29 \pm$ $0.6 \mathrm{~g}$ versus $23 \pm 1.1 \mathrm{~g}$ ), whereas decreased GN relative to right kidney weight approached significance in males $(26,000 \pm 5300$ versus $39,000 \pm 2800 \mathrm{GN} / \mathrm{g}$ ) compared with control (C) males and females. NR decreased immunoreactive angiotensin II (Ang II) type 1 receptor (AT1) in the NR kidneys at $78 \mathrm{dG}$ and increased renin at $135 \mathrm{dG}$. Immunoreactive renin decreased from 78 to $135 \mathrm{dG}$. Female fetuses had more immunoreactive Ang II type 2 receptor (AT2) than male fetuses at $78 \mathrm{dG}$ and males had more AT1 at $135 \mathrm{dG}$. The present study demonstrates gender-specific differences in fetal growth and development and in fetal kidney development in pregnancies affected by NR. (Pediatr Res 61: 42-47, 2007)
\end{abstract}

$\mathrm{T}$ The American Kidney Foundation estimates the rates of chronic renal diseases are increasing rapidly, such that 20 million Americans (one in nine adults) have some form of chronic renal disease. Similarly, epidemiologic and animal studies showing a developmental origin for renal dysfunction are also increasing (1-3). This growing body of evidence clearly shows that the kidney is sensitive to perturbations of the fetal environment. Viewed in concert with factors in modern society that may collude to impair fetal nutrition, such as poverty and drug abuse, and clinical conditions, such as hyperemesis gravidarum, anorexia nervosa, and bulimia, it is clear that decreased nutrient delivery to the fetus will affect a large number of pregnancies across socioeconomic strata (4-6).

The acquisition of renal GN is a morphogenic process that reflects sensitivity to a suboptimal intrauterine environment $(7,8)$. Reduced GN has been shown when fetal growth restric-

Received December 6, 2005; accepted August 18, 2006.

Correspondence: Mark J. Nijland, Ph.D., UT Health Science Center Medical School, Department of Obstetrics and Gynecology, MSC 7836, 7703 Floyd Curl Drive, San Antonio, TX 78229-3900; e-mail: nijland@uthscsa.edu

Supported by National Institutes of Health HD21350 and HL65399 (UT), BRIN 1P20RR16474-01 (University of Wyoming).

DOI: 10.1203/01.pdr.0000250208.09874.91 tion begins early in gestation but not when the insult is restricted to late gestation (9). Interestingly, a reduction in GN following uninephrectomy during fetal life is strongly associated with increased postnatal blood pressure $(10,11)$, whereas adult uninephrectomy is not (12). Factors that affect nephrogenesis during fetal life therefore appear to have a greater impact on blood pressure than the hypertrophic responses induced in the adult to facilitate the maintenance of filtration surface area. In accordance with this perspective, we have recently demonstrated decreased GN associated with hypertension in the male offspring of sheep NR from early to midgestation (7). From these and other studies, it is clear that although the period in which kidney development may be affected is broad, late gestation is not a part of the critical nephrogenic window in large animals such as sheep $(7,9,13,14)$.

Previous studies have shown the importance of the reninangiotensin system (RAS) in fetal renal development $(15,16)$. Several studies have shown that the intrarenal RAS of the rat neonate is perturbed as a result of maternal low-protein diets $(8,17)$. Little work in this area has been done in long-gestation species, such as the sheep, that complete nephrogenesis in utero. Further, there is a paucity of data describing the ontogeny of absolute GN and protein levels of the RAS in sheep. Thus, there remains a need to characterize the ontogeny not only of GN but also of the biochemical changes that occur during renal organogenesis to gain insights into the etiology of renal dysfunction in both the fetus and the adult.

Previous work from our group has shown 50\% global maternal NR between 0.19 and 0.50 gestation alters fetal ovarian, skeletal muscle, and cardiac development in sheep $(7,18-20)$. The intent of this study was to first document the ontogeny of renal GN and the expression of key intrarenal RAS proteins in the fetal sheep from mid- to late gestation and then to place these observations in the context of our model of maternal NR.

Abbreviations: ACE, angiotensin-converting enzyme; Ang II, angiotensin II; AT1, angiotensin II type 1 receptor; AT2, angiotensin II type 2 receptor; C, control fed 28-78 dG; CC, control fed 28-135 dG; dG, days of gestational age; GN, glomerulus number; NR, nutrient restriction/restricted; RAS, reninangiotensin system; R, NR fed 28-78 dG; RC, NR 28-78 dG, control fed $79-135 \mathrm{dG}$ 


\section{METHODS}

Animals. All experimental procedures in this study were conducted in accordance with the National Institutes of Health Guide for the Care and Use of Laboratory Animals and were approved by the University of Wyoming Institutional Animal Care and Use Committee. Multiparous Western white-faced ewes (Rambouillet $\times$ Columbia breeding) bred naturally to the same Suffolk ram were used in this study.

Animal groupings for two different experiments are described. 1) Thirty-two pregnant ewes were selected for use in the NR study and divided into two cohorts with 16 ewes each. Age- and weight-matched ewes were placed into two study cohorts destined for study at either midgestation $[78 \mathrm{~d}$ of gestation $(\mathrm{dG})]$ or late gestation $(135 \mathrm{dG})$. In the $78-\mathrm{dG}$ cohort, there were two experimental groups: animals fed from 28 to $78 \mathrm{dG}(\mathrm{C})$ and animals fed $50 \%$ of the $\mathrm{C}$ diet from 28 to $78 \mathrm{dG}(\mathrm{R})$. Two experimental groups were also defined in the 135-dG cohort: animals fed from 28 to $135 \mathrm{dG}$ (CC) and animals fed $50 \%$ of the $\mathrm{C}$ diet from 28 to $78 \mathrm{dG}$ followed by re-alimentation to $\mathrm{C}$ from 79 to $135 \mathrm{dG}$ (RC). Diets were calculated based on $\mathrm{C}=100 \%$ of National Research Council daily rations for a pregnant ewe while assuming $150 \%$ lambing rate. The NR protocol has been described previously in detail (7,18-20). The four groups (C, R, CC, and RC) each contained ewes carrying four singleton and four twin pregnancies. One fetus from each twin pregnancy was randomly selected for study. The gender distribution of the fetuses in the $\mathrm{C}, \mathrm{CC}, \mathrm{R}$, and $\mathrm{RC}$ groups at mid- and late gestation is shown in Table 1.

[2] In addition to the control animals ( $\mathrm{dG} 78$ and 135) from the NR study (described above) fetal kidneys were obtained from other ongoing studies at dG $90(n=4), 100(n=6)$, and $120(n=15)$ for assessment of the ontogeny of glomerulus number. On day of necropsy, pregnant ewes were euthanized as described previously $(7,18-20)$. Kidneys were cleansed of extraneous connective tissues and snap frozen in liquid nitrogen and stored at $-80^{\circ} \mathrm{C}$ until further analysis.

Acid maceration and glomerulus counting. The method of acid maceration used in the present study is an adaptation of a method published previously (7). Right kidneys were decapsulated and placed in 50\% $\mathrm{HCl}$ at room temperature for $1-6 \mathrm{~h}$ (depending on kidney weight). $\mathrm{HCl}$ was decanted, the kidneys were rinsed with three volumes of tap water, and stored overnight at $4^{\circ} \mathrm{C}$. The kidney was dispersed and brought to a final volume of $750-2000 \mathrm{~mL}$ of tap water (depending on kidney weight). Kidneys were coded to blind the investigator to the experimental groups to which each sample belonged. The kidney solution was thoroughly mixed, and four $250-\mu \mathrm{L}$ aliquots were each counted in duplicate as described previously (7). Several kidneys from each age were counted in triplicate to establish an $8 \%$ coefficient of variation for the procedure.

Western blot analysis. Total soluble protein was obtained and quantified as described previously $(7,21)$. Fifty micrograms of total protein was separated by sodium dodecyl sulfate-polyacrylamide gel electrophoresis and transferred to a polyvinylidene fluoride membrane as described previously $(7,21)$. Membranes were blocked for $1 \mathrm{~h}$ to reduce nonspecific binding using 5\% nonfat milk in Tris-buffered saline with $0.01 \%$ Tween (TBS-T). Immunodetection of the following proteins was accomplished as described previously $(7,21)$, using commercially available polyclonal antibodies raised in rabbit against human peptide sequences for AT1 (306), AT2 (H-143), renin (H-105) (Santa Cruz Biotechnology; Santa Cruz, CA), or monoclonal antibody raised in mice against full length human ACE (3500; Chemicon International, Temecula, $\mathrm{CA}$ ) and a peptide segment of human $\beta$-actin (Ab8227; Abcam, Cambridge, MA). In brief, membranes were incubated $1 \mathrm{~h}$ in primary antibody solutions (renin 1:400, AT1 and AT2, 1:500; ACE: 1:1000) and then washed $3 \times 5$ min each. Membranes were then incubated in secondary horseradish peroxidase-conjugated antibodies [AT1, AT2, and renin 1:1000 goat anti-rabbit (Santa Cruz); ACE, 1:5000 goat antimouse (Chemicon)] for $1 \mathrm{~h}$ and washed $3 \times 5 \mathrm{~min}$. Proteins were revealed using West Pico Supersignal (Pierce) chemiluminescent substrate and exposed to film $10-120 \mathrm{~s}$ as needed (Kodak Biomax).

Table 1. Fetal morphometry at mid-and late gestation

\begin{tabular}{|c|c|c|c|c|c|c|}
\hline Mid-gestation (78 dG) & \multicolumn{3}{|c|}{$\mathrm{C}$} & \multicolumn{3}{|c|}{ NR } \\
\hline Fetal Weight $(\mathrm{g})$ & $280 \pm 7.8$ & $290 \pm 3.3 \S$ & $250 \pm 7.0$ & $280 \pm 11$ & $300 \pm 1.3 \S$ & $260 \pm 15$ \\
\hline Glomerulus Number $(\mathrm{GN}) \times 10^{3}$ & $62.0 \pm 3.8$ & $59.0 \pm 4.5$ & $68.0 \pm 6.4$ & $58.0 \pm 5.5$ & $63.0 \pm 4.4$ & $55.0 \pm 8.6$ \\
\hline \multirow[t]{2}{*}{ GN/Right $\mathrm{KW} \times 10^{3}$} & $43.0 \pm 2.2$ & $39.0 \pm 2.3$ & $48.0 \pm 1.3$ & $43.0 \pm 2.6$ & $43.0 \pm 4.5$ & $44.0 \pm 3.6$ \\
\hline & \multicolumn{3}{|c|}{$\mathrm{CC}$} & \multicolumn{3}{|c|}{ NRR } \\
\hline Fetal Weight $(\mathrm{kg})$ & $5.2 \pm 0.2$ & $5.3 \pm 0.3$ & $5.0 \pm 0.3$ & $5.2 \pm 0.2$ & $5.6 \pm 0.2$ & $4.8 \pm 0.1$ \\
\hline Combined Kidney Weight $(\mathrm{KW}, \mathrm{g})$ & $24 \pm 1.1$ & $23 \pm 1.1$ & $24 \pm 2.1$ & $26 \pm 1.1$ & $29 \pm 0.6^{*}$ & $23 \pm 0.9$ \\
\hline Glomerulus Number $(\mathrm{GN}) \times 10^{3}$ & $490 \pm 49$ & $540 \pm 10$ & $450 \pm 49$ & $420 \pm 60$ & $370 \pm 84$ & $460 \pm 92$ \\
\hline GN/Right $\mathrm{KW} \times 10^{3}$ & $40 \pm 2.8$ & $39 \pm 2.8$ & $41 \pm 6.1$ & $33 \pm 5.4$ & $26 \pm 5.3 * *$ & $41 \pm 8.3$ \\
\hline
\end{tabular}

Fetal weight, total kidney weights, and GN during midgestation in C and 50\% NR sheep fetuses at mid- (78 dG) and late (135 dG) gestation; $\S$ Different from females of same dietary group $(p<0.05)$; * Different from C group of the same sex $(p<0.05)$; ** Different from all groups at mid- and late gestation $(p<0.05)$. 
$\beta$-Actin was used as a loading control, and measurement was performed after each membrane was tested for the primary protein of interest (AT1, AT2, ACE, renin). Membranes were stripped of previously applied antibodies using a commercially available buffer (Restore; Pierce). Membranes were washed $3 \times 5 \mathrm{~min}$ and blocked for $1 \mathrm{~h}$ before developing for $\beta$-actin as described above.

Images were optically scanned (Hewlett-Packard 5200C with HP PrecisionScan software v2.02) and digitized, and antigen signal was quantified by pixel density (Un Scan It gel v5.1; Silk Scientific, Orem, UT). Quantification was performed only after linearity was established between the amount of protein and film exposure time.

Statistical analysis and calculations. All data are presented as mean \pm SEM except where indicated. Western blot data are presented as the ratio of each protein of interest to $\beta$-actin. Kidney weight $(\mathrm{KW})$ is presented as the sum of both kidneys. GN/KW was calculated per gram of right KW. Statistical comparisons were made using a $t$ test, analysis of variance (ANOVA) or two-way ANOVA where appropriate with significance accepted when $p<0.05$ (GraphPad Prism v4.00 for Windows; GraphPad Software, San Diego, CA).

\section{RESULTS}

\section{Kidney and Fetus Morphometry}

Midgestation. Across dietary groups, male fetuses were $16 \%$ heavier than female fetuses in both the $\mathrm{C}$ and $\mathrm{R}$ groups at midgestation. In accordance with increased body weight, the male fetuses also had larger kidneys than the female fetuses $(p<0.05)$. NR did not reduce either fetal weight or $\mathrm{KW}$ at midgestation in the present study (Table 1).

Late gestation. RC male fetuses had heavier kidneys than male $\mathrm{C}$ fetuses $(p<0.05$; Table 1). Fetal weights were not different between $\mathrm{CC}$ and $\mathrm{RC}$ animals at $135 \mathrm{dG}$ (Table 1).

\section{Glomerulus Number}

Ontogeny. Figure 1 illustrates the change in GN across the last half of gestation in the fetal sheep: $78 \mathrm{dG}(0.53$ of gestation), $90 \mathrm{dG}(0.60), 100 \mathrm{dG}(0.68), 120 \mathrm{dG}(0.82)$, and 135 (0.92). No differences were observed in GN between male and female fetuses at any gestational age. Therefore, data were pooled across sex.
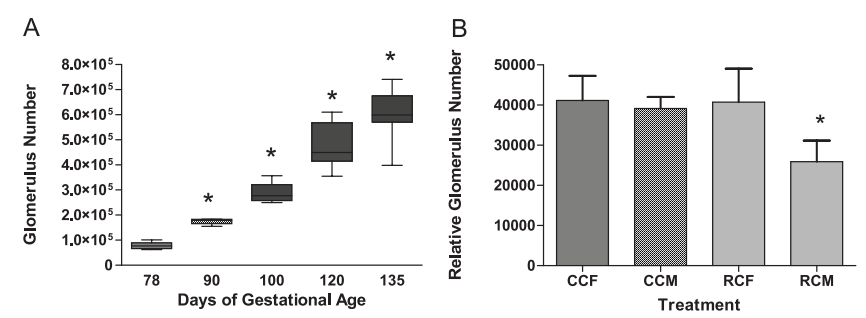

Figure 1. Glomerulus number. Ontogeny $(A)$ and effect of NR on relative GN $(B)$. (A) GN increased between each gestational age evaluated. Data are shown as a box and whisker plot indicating the median and the first and third quartiles. (*Different from previous gestational age; $p<0.05$, ANOVA). (B) $50 \%$ NR during $28-78 \mathrm{dG}$ resulted in fewer glomeruli per gram of $\mathrm{KW}$ in the male but not female kidneys at $135 \mathrm{dG}\left({ }^{*} p<0.05\right.$, ANOVA).

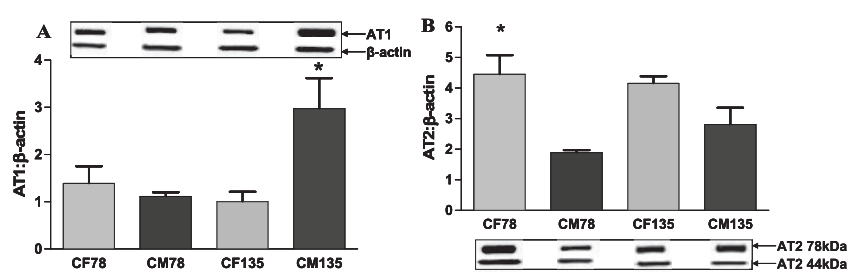

Figure 2. Ontogeny of AT1 $(A)$ and AT2 $(B)$ expression in male and female fetuses at mid- and late gestation. Immunoreactive AT1 $(A)$ and AT2 $(B)$ at 78 and $135 \mathrm{dG}$. AT1 was greater $(* p<0.05)$ in the control male $135 \mathrm{dG}$ $(\mathrm{CM} 135, n=4)$ fetal kidneys than in the CM78 $(n=5)$, control female $(\mathrm{CF} 78, n=3)$ or CF $135(n=4)$ fetal kidneys. AT2 was greater $\left({ }^{*} p<0.05\right)$ in the CF78 $(n=3)$ than the CM78 fetal kidneys. Figure depicts both observed AT2 bands ( 78 and $44 \mathrm{kD}$ ), and data represent the sum of both bands.

Effects of NR. Absolute GN and GN relative to right KW were not different between $\mathrm{C}$ and $\mathrm{R}$ groups at $78 \mathrm{dG}$, nor was any difference apparent between the sexes (Table 1). The number of glomeruli expressed relative to right $\mathrm{KW}$ was constant between 78 and $135 \mathrm{dG}$ in all groups except the RC male, in which it was decreased $(p<0.05)$. Absolute GN was decreased $18 \%$ in the male RC kidneys compared with the male CC kidney, although this was not significant (Table 1).

\section{Protein Expression}

Ontogeny. Immunoreactive AT1 was observed as a $67-\mathrm{kD}$ band and increased from 78 to $135 \mathrm{dG}$ in the male fetuses but not in the female fetuses (Fig. 2A). Total immunoreactive AT2, observed as two bands at 44 and $78 \mathrm{kD}$, was higher in the female 78-dG fetuses than in the 78-dG male fetuses and remained unchanged at $135 \mathrm{dG}$ in both male and female fetuses (Fig. 2B). Immunoreactive ACE was observed as a single $170-\mathrm{kD}$ band and remained unchanged from 78 to 135 $\mathrm{dG}$ in the kidneys of both the male $(0.80 \pm 0.19$ versus $0.69 \pm 0.10)$ and female $(0.93 \pm 0.12$ versus $0.53 \pm 0.15)$ fetuses. Immunoreactive renin was observed as two bands, prorenin at $52 \mathrm{kD}$ and active renin at $37 \mathrm{kD}$, and decreased from 78 to $135 \mathrm{dG}$ (Fig. 3A).

Effects of NR. At midgestation, immunoreactive AT1 decreased in the R fetal kidney compared with $\mathrm{C}(0.17 \pm 0.03$ versus $0.31 \pm 0.05 ; p<0.05$ ), although no difference was found when fetal gender was considered. AT2 $(2.95 \pm 0.46$ versus $2.56 \pm 0.26)$, ACE $(0.85 \pm 0.12$ versus $0.69 \pm 0.09)$,
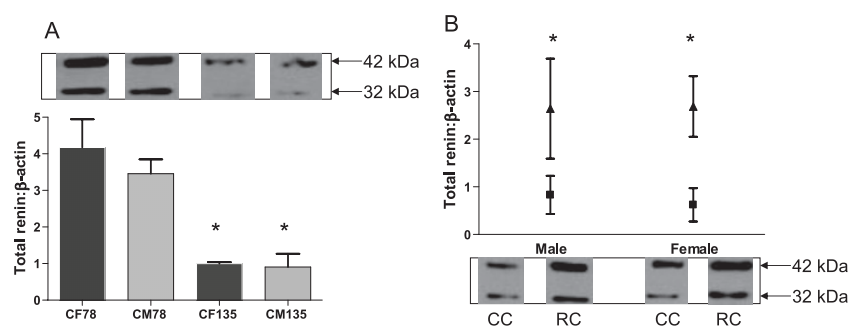

Figure 3. Renal renin immunoreactivity. Ontogeny $(A)$ and effect of NR $(B)$. Immunoreactive renin-to- $\beta$-actin ratio decreased from 78 to $135 \mathrm{dG}$. $(B)$ Immunoreactive renin was increased in the male and female RC $(\mathbf{\Lambda})$ compared with the $\mathrm{CC}(\mathbf{\square})$ fetuses at $135 \mathrm{dG}\left({ }^{*} p<0.05\right)$. Figure depicts both observed prorenin and renin (52 and $37 \mathrm{kD})$, and data represent the sum of both bands. 
and renin immunoreactivity was not different between $\mathrm{C}$ and $\mathrm{R}$ fetuses, and no gender effects was observed.

Immunoreactive renin was increased in the RC male and female fetuses at dG 135 (Fig. 3B). No differences were noted in immunoreactive AT1, AT2 $(3.85 \pm 0.65$ versus $3.02 \pm$ $0.33)$, and $\mathrm{ACE}(0.58 \pm 0.09$ versus $0.59 \pm 0.09)$ between the $\mathrm{CC}$ and $\mathrm{RC}$ groups at $135 \mathrm{dG}$.

\section{DISCUSSION}

The present study was designed to evaluate the ontogeny of GN and the intrarenal RAS in the ovine fetal kidney and the effects of 50\% global NR during early to midgestation on GN and the intrarenal RAS. We report several important findings in this study: 1) there are gender differences in fetal weight and in the ontogeny of protein expression for AT1 and AT2, a phenomenon only recently described for intrarenal gene expression in a study using murine gene arrays (22); 2) $50 \%$ global NR of the pregnant ewe from 28 to $78 \mathrm{dG}$ elicited decreased AT1 at $78 \mathrm{dG}$ and increased renin at $135 \mathrm{dG}$ that is independent of a reduction in body weight; and 3) following re-alimentation, 135-dG male fetuses exhibit a reduction in GN (whereas female fetuses do not).

The present data indicate that GN in the sheep rapidly increases between midgestation and achieves its culmination at 0.9 of gestation. No significant increase in GN was observed between $135 \mathrm{dG}$ and our previously reported measurement in wethers at 9 mo of age (7), indicating that the generation of new glomeruli has largely been completed by late gestation. These findings are in agreement with those of previous studies in the sheep (23) and the baboon (24), both species in which glomerulogenesis terminates before birth.

In the present study, we evaluated steady-state protein expression as an assessment of the molecular phenotype of the fetal kidney. Consequently, it is beyond the scope of the present study to ascribe possible transcriptional, posttranscriptional, or translational regulatory mechanisms for the gene products studied. The RAS is known to be important in renal development $(25,26)$. Recent work has demonstrated innate gender differences in gene transcription of osmoregulatory and drug-metabolizing proteins in the kidney (22), and a previous study reported a trend toward higher AT2 and lower AT1 in fetal kidneys from female microswine (27). Moreover, investigators have held for some time that the RAS contributes significantly to the observed differences between the sexes in the progression of renal disease (28).

Presently, AT1 immunoreactivity was increased from 78 to $135 \mathrm{dG}$ in male but not female fetuses. Previous studies have reported increased AT1 in late gestation, but no discrimination has been made between male and female fetuses $(15,29)$. We show that immunoreactive AT2 decreased in the female but not male fetuses from mid- to late gestation, a finding in females that is in agreement with previous studies that have reported decreased AT2 mRNA from mid- to late gestation (15). Although immunoreactive ACE did not change from mid- to late gestation, renin decreased from 78 to $135 \mathrm{dG}$, but no gender effect was observed. A previous study reported no change in renin mRNA from 90 to $134 \mathrm{dG}$ but did show a significant decrease between late gestation and post partum (30).

Previous studies have not evaluated the effects of fetal gender on gene expression or reported numbers of male and female fetuses in the study cohorts, making retrospective comparison impossible. The mechanisms underlying the observed gender dichotomy in AT1 and AT2 remain unclear. Previous authors have recognized a gender dichotomy in the progression of renal disease and have suggested a central role for the RAS (28). The present data support this hypothesis, although further studies are needed to elucidate the sex differences in the regulation of AT1 expression.

No effect of NR was seen at midgestation on fetal or kidney weight or on GN when evaluated for gender differences or when gender data were combined. This is not unreasonable because previous studies have been equivocal on fetal weight after NR $(7,18-20,31)$ and it appears that only $10 \%$ of the final complement of glomeruli has been attained at this point. It is recognized that a possible limitation of the methodology used in this study is a loss of immature glomeruli during sample preparation. Nevertheless, this is unlikely to have changed our findings because only a small portion of glomerulogenesis has occurred by midgestation.

The present data show that $135-\mathrm{dG}$ male fetuses that were NR from early to midgestation and then re-alimented have fewer glomeruli per gram of $\mathrm{KW}$ than $\mathrm{C}$ males and females from both dietary treatment groups. Absolute GN in these animals decreased 18\%. Although this reduction was not statistically significant, it is similar to previous studies with greater sample sizes reporting reduced GN from maternal NR from d 12 to term in rats (8). In contrast, a previous study that used a low-protein diet during pregnancy demonstrated similar decreases in nephron number in both male and female offspring (32). The reasons underlying the gender differences observed in fetal nephron endowment following maternal NR reported in the present study remain unclear. It is possible that there are innate differences between male and female kidneys, as recently reported by Rinn et al. (22), and therefore it is conceivable that male and female fetuses respond to NR differently. Further, Tamimi et al. (33) reported mothers of male babies eat more than mothers of females. Viewed together with the present study, it appears that the male fetuses require a higher plane of nutrition than female fetuses and may therefore be more susceptible to NR. It also appears that, in contrast to maternal low-protein diets in rats (32), the NR stress in the present study may not have been severe enough to elicit effects in both fetuses.

Several changes were observed with respect to protein expression as a consequence of NR. Immunoreactive AT1 was decreased at $78 \mathrm{dG}$, whereas renin was increased in the RC kidneys at dG 135 but not at $78 \mathrm{dG}$. Previous authors have suggested AT1 as an important mediator of branching morphogenesis in the fetal kidney (34). Others have demonstrated dysregulation of the intrarenal RAS in rat models of programmed hypertension $(8,17,35,36)$. The present finding of reduced immunoreactive AT1 in the NR kidney is consistent with the hypothesis that NR mediates impaired nephron development via AT1 and Ang II signaling (37). Similarly, 
disruption of Ang II signaling by ACE inhibition or AT1 antagonism both result in altered renal development (25). This finding is in agreement with a recent report by Vehaskari et al. (17) demonstrating decreased AT1 protein levels in 1-d-old rat pups of protein-restricted dams in an established model of in utero programmed hypertension. The renin increase in the late gestation kidney of the RC group is difficult to interpret at present, although it may presage the onset of hypertension that we have previous reported in the male offspring (7). Previous work has shown that renin mRNA levels are sensitive to alterations in the intrarenal kinin-kallikrein system (KKS) (38); thus, the potential for crosstalk between the KKS and the RAS cannot be ruled out in our model of NR.

A driving force for the study of the ontogeny of nephrogenesis in the fetal kidney is to gain better understanding of the critical time points in development at which perturbation of the in utero environment can alter the trajectory of renal development. This has implications not only for fetal NR and the teratogenic effects of substances/activities encountered by the mother during pregnancy, but also for renal development in premature infants. Preterm delivery has increased substantially over the past $10 \mathrm{y}$, increasing to as high as $10 \%$ of births in the Western world (39). Because recent advances in neonatal care have increased the chances of survival to $80 \%$ (40), understanding the effects of prematurity on fetal renal development is important and clinically relevant. The premature infant is a fetus that will finalize renal maturation ex utero. Although this is the norm for kidney development in species such as the rat and the pig, long-gestation species such as the sheep and the human normally complete renal development in utero. Clinical data indicate that neonatal mortality of neonates with acute renal failure remains quite high (30\%-60\%), suggesting that renal immaturity has severe physiologic consequences and that much remains unknown about the transition from intrauterine to extrauterine renal function (40).

Summary. The data reported in the present study support the hypothesis that maternal NR during early to midgestation alters the trajectory of renal organogenesis and renal maturation in the ovine fetus. These effects were observed at both the molecular and organ levels demonstrating a systemwide disruption of renal organogenesis. Decreased GN has been related to increased blood pressure in the sheep (7) and other animal models $(32,37)$. These results show definitively that the decreased nephron number is generated in utero and is not a postnatal effect of elevated blood pressure (7). We also report NR during early to midgestation increased renin in the late-gestation fetal kidney, an event that may presage later hypertension in these animals. The present study demonstrates altered renal development in utero and in doing so provides a substrate for the future development of hypertension. These findings may also provide insight for further studies examining gender differences in the progression of renal disease.

Acknowledgments. The authors acknowledge Dr. Graham Mitchell and Carole Hertz for their contributions. The NR paradigm was provided by the Center for the Study of Fetal Programming at the University of Wyoming.

\section{REFERENCES}

1. Brenner BM, Garcia DL, Anderson S 1988 Glomeruli and blood pressure. Less of one, more the other? Am J Hypertens 1:335-347

2. Merlet-Benichou C, Gilbert T, Muffat-Joly M, Lelievre-Pegorier M, Leroy B 1994 Intrauterine growth retardation leads to a permanent nephron deficit in the rat. Pediatr Nephrol 8:175-180

3. Merlet-Benichou C 1999 Influence of fetal environment on kidney development. Int J Dev Biol 43:453-456

4. Hickey CA, Kreauter M, Bronstein J, Johnson V, McNeal SF, Harshbarger DS, Woolbright LA 1999 Low prenatal weight gain among adult WIC participants delivering term singleton infants: variation by maternal and program participation characteristics. Matern Child Health J 3:129-140

5. Stewart DE, Raskin J, Garfinkel PE, MacDonald OL, Robinson GE 1987 Anorexia nervosa, bulimia, and pregnancy. Am J Obstet Gynecol 157:1194-1198

6. Franko DL, Spurrell EB 2000 Detection and management of eating disorders during pregnancy. Obstet Gynecol 95:942-946

7. Gilbert JS, Lang AL, Grant AR, Nijland MJ 2005 Maternal nutrient restriction in sheep: hypertension and decreased nephron number in offspring at 9 months of age. J Physiol 565:137-147

8. Woods LL, Ingelfinger JR, Nyengaard JR, Rasch R 2001 Maternal protein restriction suppresses the newborn renin-angiotensin system and programs adult hypertension in rats. Pediatr Res 49:460-467

9. Mitchell EK, Louey S, Cock ML, Harding R, Black MJ 2004 Nephron endowment and filtration surface area in the kidney after growth restriction of fetal sheep. Pediatr Res 55:769-773

10. Moritz KM, Wintour EM, Dodic M 2002 Fetal uninephrectomy leads to postnatal hypertension and compromised renal function. Hypertension 39:1071-1076

11. Woods LL 1999 Neonatal uninephrectomy causes hypertension in adult rats. Am J Physiol 276:R974-R978

12. Goldfarb DA, Matin SF, Braun WE, Schreiber MJ, Mastroianni B, Papajcik D, Rolin HA, Flechner S, Goormastic M, Novick AC 2001 Renal outcome 25 years after donor nephrectomy. J Urol 166:2043-2047

13. Wintour EM, Moritz KM, Johnson K, Ricardo S, Samuel CS, Dodic M 2003 Reduced nephron number in adult sheep, hypertensive as a result of prenatal glucocorticoid treatment. J Physiol 549:929-935

14. Brennan KA, Gopalakrishnan GS, Kurlak L, Rhind SM, Kyle CE, Brooks AN, Rae MT, Olson DM, Stephenson T, Symonds ME 2005 Impact of maternal undernutrition and fetal number on glucocorticoid, growth hormone and insulin-like growth factor receptor mRNA abundance in the ovine fetal kidney. Reproduction 129:151159

15. Robillard JE, Page WV, Mathews MS, Schutte BC, Nuyt AM, Segar JL 1995 Differential gene expression and regulation of renal angiotensin II receptor subtypes (AT1 and AT2) during fetal life in sheep. Pediatr Res 38:896-904

16. Segar JL, Bedell K, Page WV, Mazursky JE, Nuyt AM, Robillard JE 1995 Effect of cortisol on gene expression of the renin-angiotensin system in fetal sheep. Pediatr Res 37:741-746

17. Vehaskari VM, Stewart T, Lafont D, Soyez C, Seth D, Manning J 2004 Kidney angiotensin and angiotensin receptor expression in prenatally programmed hypertension. Am J Physiol Renal Physiol 287:F262-F267

18. Vonnahme KA, Hess BW, Hansen TR, McCormick RJ, Rule DC, Moss GE, Murdoch WJ, Nijland MJ, Skinner DC, Nathanielsz PW, Ford SP 2003 Maternal undernutrition from early- to mid-gestation leads to growth retardation, cardiac ventricular hypertrophy, and increased liver weight in the fetal sheep. Biol Reprod 69:133-140

19. Zhu MJ, Ford SP, Nathanielsz PW, Du M 2004 Effect of maternal nutrient restriction in sheep on the development of fetal skeletal muscle. Biol Reprod 71:1968-1973

20. Dong F, Ford SP, Fang CX, Nijland MJ, Nathanielsz PW, Ren J 2005 Maternal nutrient restriction during early to mid gestation up-regulates cardiac insulin-like growth factor (IGF) receptors associated with enlarged ventricular size in fetal sheep. Growth Horm IGF Res 15:291-299

21. Gilbert JS, Lang AL, Nijland MJ 2005 Maternal nutrient restriction and the fetal left ventricle: Decreased angiotensin receptor expression. Reprod Biol Endocrinol 3:27

22. Rinn JL, Rozowsky JS, Laurenzi IJ, Petersen PH, Zou K, Zhong W, Gerstein M, Snyder M 2004 Major molecular differences between mammalian sexes are involved in drug metabolism and renal function. Dev Cell 6:791-800

23. Robillard JE, Weismann DN, Herin P 1981 Ontogeny of single glomerular perfusion rate in fetal and newborn lambs. Pediatr Res 15:1248-1255

24. Gubhaju L, Black MJ 2005 The baboon as a good model for studies of human kidney development. Pediatr Res 58:505-509

25. Tufro-McReddie A, Romano LM, Harris JM, Ferder L, Gomez RA 1995 Angiotensin II regulates nephrogenesis and renal vascular development. Am J Physiol 269:F110-F115

26. Yoo KH, Wolstenholme JT, Chevalier RL 1997 Angiotensin-converting enzyme inhibition decreases growth factor expression in the neonatal rat kidney. Pediatr Res 42:588-592

27. Bagby SP, LeBard LS, Luo Z, Ogden BE, Corless C, McPherson ED, Speth RC 2002 ANG II AT(1) and AT(2) receptors in developing kidney of normal microswine. Am J Physiol Renal Physiol 283:F755-F764

28. Sandberg K, Ji H 2003 Sex and the renin angiotensin system: implications for gender differences in the progression of kidney disease. Adv Renal Replace Ther 10:15-23

29. Robillard JE, Schutte BC, Page WV, Fedderson JA, Porter CC, Segar JL 1994 Ontogenic changes and regulation of renal angiotensin II type 1 receptor gene expression during fetal and newborn life. Pediatr Res 36:755-762

30. Zhang DY, Lumbers ER, Simonetta G 1996 Changes in renal renin gene expression in fetal sheep. Clin Exp Pharmacol Physiol 23:682-684 
31. Whorwood CB, Firth KM, Budge H, Symonds ME 2001 Maternal undernutrition during early to midgestation programs tissue-specific alterations in the expression of the glucocorticoid receptor, 11beta-hydroxysteroid dehydrogenase isoforms, and type 1 angiotensin ii receptor in neonatal sheep. Endocrinology 142:2854-2864

32. Vehaskari VM, Aviles DH, Manning J 2001 Prenatal programming of adult hypertension in the rat. Kidney Int 59:238-245

33. Tamimi RM, Lagiou P, Mucci LA, Hsieh CC, Adami HO, Trichopoulos D 2003 Average energy intake among pregnant women carrying a boy compared with a girl. BMJ 326:1245-1246

34. Yosypiv IV, El-Dahr SS 2005 Role of the renin-angiotensin system in the development of the ureteric bud and renal collecting system. Pediatr Nephrol 20:1219-1229

35. Sahajpal V, Ashton N 2003 Renal function and angiotensin AT1 receptor expression in young rats following intrauterine exposure to a maternal low-protein diet. Clin Sci (Lond) 104:607-614
36. McMullen S, Gardner DS, Langley-Evans SC 2004 Prenatal programming of angiotensin II type 2 receptor expression in the rat. Br J Nutr 91:133-140

37. Woods LL, Rasch R 1998 Perinatal ANG II programs adult blood pressure, glomerular number, and renal function in rats. Am J Physiol 275:R1593-R1599

38. Yosipiv IV, Dipp S, El-Dahr SS 2001 Targeted disruption of the bradykinin B2 receptor gene in mice alters the ontogeny of the renin-angiotensin system. Am J Physiol Renal Physiol 281:F795-F801

39. Lumley J 2003 Defining the problem: the epidemiology of preterm birth. Br J Obstet Gynaecol 110:3-7

40. Lemons JA, Bauer CR, Oh W, Korones SB, Papile LA, Stoll BJ, Verter J, Temprosa M, Wright LL, Ehrenkranz RA, Fanaroff AA, Stark A, Carlo W, Tyson JE, Donovan EF, Shankaran S, Stevenson DK 2001 Very low birth weight outcomes of the National Institute of Child health and human development neonatal research network, January 1995 through December 1996. NICHD Neonatal Research Network. Pediatrics 107:E1 